POSSIBILIDADES HERMENÊUTICAS PARA A APRECIAÇÃO JUDICIAL DE OMISSÕES INCONSTITUCIONAIS ADMINISTRATIVAS: o controle da inconstitucionalidade por omissão no Constitucionalismo Contemporâneo

\title{
Isadora Ferreira Neves ${ }^{1}$
}

RESUMO: Este trabalho aborda a relação das omissões inconstitucionais com os pressupostos do Constitucionalismo Contemporâneo. Para tanto, toca-se no ponto de distinção entre as variedades de omissões inconstitucionais, passando pelos elementos conceituais que caracterizam as omissões inconstitucionais administrativas. Num segundo momento, propõe-se a análise das questões que envolvem as omissões inconstitucionais administrativas sob a perspectiva do paradigma hermenêutico. A partir de uma pesquisa bibliográfica associada com pesquisa documental jurisprudencial, tem-se como objetivo discutir as omissões inconstitucionais administrativas causadas pela proteção insuficiente de direitos fundamentais sob o prisma do paradigma hermenêutico. Para atingir tal objetivo, em um primeiro momento, observa-se a evolução de modelos estatais que transitam de postura inertes a posturas inclusivas por parte do poder público. Torna-se então relevante analisar o papel do Poder Judiciário enquanto concretizador de direitos fundamentais que envolve também uma leitura do Constitucionalismo Contemporâneo e a necessidade de efetivação de direitos fundamentais para uma democracia substancial. Além disso, o estudo discute a inconstitucionalidade por omissão ocasionada pela proteção insuficiente de direitos fundamentais, analisando as diferentes possibilidades de omissões inconstitucionais, bem como o julgamento da Ação Direta de Inconstitucionalidade por Omissão $\mathrm{n}^{0} 1.698$ para suscitar o debate dos pontos abordados no contexto da jurisdição constitucional brasileira.

PALAVRAS-CHAVE: omissões inconstitucionais, constitucionalismo contemporâneo, poder judiciário.

\section{INTRODUÇÃO}

O papel central dos direitos fundamentais na teoria do direito eleva-se diante do conjunto de textos constitucionais surgidos após a Segunda Guerra Mundial, que não se restringiam a estabelecer as competências e separar os poderes públicos, mas que continham normas materiais ou substantivas que condicionam a atuação do Estado por meio da ordenação de certos fins e objetivos. (CARBONELL, 2007, p. 9).

\footnotetext{
${ }^{1}$ Doutoranda em Direito Público pela Universidade do Vale do Rio dos Sinos (Unisinos) como bolsista CAPES/PROEX e membro do Dasein - Núcleo de Estudos Hermenêuticos, coordenado pelo Prof. Dr. Lenio Luiz Streck. Mestre em Direito Público pela UNISINOS (2014). Pós - Graduada em Direito Público pela Faculdade Independente do Nordeste - FAINOR (2009). Graduada em Direito pela Universidade Estadual de Santa Cruz - UESC (2009). Universidade do Vale do Rio dos Sinos - UNISINOS - Brasil. ORCID iD:https://orcid.org/0000-0003-0428-0807 Lattes: http://lattes.cnpq.br/6778278829147343 E-mail: isadoraneves@hotmail.com
} 
As Constituições passam então a se caracterizar por conter amplos catálogos de direitos fundamentais, o que renova a relação entre o Estado e os cidadãos, a exemplo da Constituição brasileira de 1988. Nesse contexto, eleva-se a importância de abordagens teóricas que discutam os limites do Welfare Stare e a legitimidade do Poder Judiciário para lidar com a complexidade das demandas que envolvam a concretização de direitos constitucionais, na medida em que tal perspectiva de Estado, ainda social, não rompe com o modelo econômico capitalista que não se baseia na inclusão social. (MORAIS; BRUM, 2016, p. 104).

Torna-se então irrefutável a importância da jurisdição como possibilidade de acesso aos direitos fundamentais, que acarreta os fenômenos da judicialização da política (fenômeno contingencial derivado da necessidade de concretizar direitos existentes) e do ativismo judicial (derivado de decisões judiciais que aplicam o direito como fruto da vontade do julgador) ${ }^{2}$. Ocorre que todos esses aspectos necessitam ainda estar alinhados com uma cadeia de precedentes íntegra e coerente a respeito do controle judicial de políticas públicas, sob pena de o Judiciário atuar concretizando "direitos egoísticos travestidos hermeneuticamente de direitos constitucionais", na expressão de Guilherme Brum e de José Bolzan de Morais. (MORAIS; BRUM, 2016, p. 105106).

Considerando as transformações que integram o Constitucionalismo Contemporâneo, tanto no tocante à ampliação do rol de direitos fundamentais, especialmente aqueles que geram prestações positivas do poder público bem como a atuação do Poder Judiciário na realização desses direitos, o trabalho tem como ponto central a abordagem dessas questões no que tange ao não fazer estatal. O presente trabalho tem como foco de análise, nessa linha, a apreciação judicial das omissões inconstitucionais administrativas a partir do paradigma hermenêutico e sua relação com a manutenção dos pressupostos do Constitucionalismo Contemporâneo.

Ao consultar a produção bibliográfica e também o repertório jurisprudencial a respeito da inconstitucionalidade por omissão no direito brasileiro, predomina a abordagem que reduz o tema ao fenômeno das omissões normativas ou legislativas, ou seja, à inércia do ente competente quanto ao cumprimento do dever de regulamentar, imposto por assim denominadas "normas constitucionais de eficácia limitada", normas compreendidas como pendentes de regulamentação para que possam produzir os seus plenos efeitos ${ }^{3}$.

\footnotetext{
${ }^{2}$ Sobre o problema do ativismo judicial a sua distinção do fenômeno da judicialização da política ver, entre outros: TASSINARI, Clarissa. Jurisdição e ativismo judicial: limites da atuação do Judiciário. Porto Alegre: Livraria do Advogado, 2013.

${ }^{3}$ A profusão de textos que se concentram em abordar o problema das omissões normativas pode ilustrar a afirmação supra. Ver, entre outros: COÊLHO, Marcus Vinícius Furtado. Mandado de injunção e efetividade dos direitos e liberdades constitucionais. Consultor Jurídico. 5 dez. 2016. Disponível em: < https://www.conjur.com.br/2016-dez-05/mandado-injuncao-efetividade-direitos-liberdades?imprimir=1>. Acesso em: 15 out. 2016; VALLE, André Rufino do. Até que enfim, uma lei para o Mandado de Injunção.
} 
Ocorre que, ao se adotar a perspectiva de Constitucionalismo Contemporâneo e de Estado Democrático de Direito como elementos associados à vinculação dos poderes públicos ao projeto estatal delineado no texto constitucional (o plus normativo, conceito a ser desenvolvido mais detalhadamente no embasamento teórico), é inevitável a conclusão de que tanto a inércia tocante ao dever de regulamentar quanto àquela referente à concretização de direitos fundamentais através de políticas públicas são elementos de provocação do problema da inconstitucionalidade por omissão.

Assumindo tais premissas acima apontadas, o conteúdo deste trabalho delimita-se ao enfrentamento dos seguintes temas:

Em primeiro lugar, a abordagem da relação das omissões inconstitucionais com os pressupostos do Constitucionalismo Contemporâneo. Para tanto, é preciso tocar no ponto de distinção entre as variedades de omissões inconstitucionais, passando pelos elementos conceituais que caracterizam as omissões inconstitucionais administrativas. Ainda num primeiro momento, premente a delimitação do tema no sentido de passar pelos marcos teóricos que envolvem a vinculação dos poderes públicos aos ditames constitucionais assim como a atuação do Poder Judiciário como concretizador de direitos.

Num segundo momento, como aspecto propositivo e problematizador, propõe-se a análise das questões que envolvem as omissões inconstitucionais administrativas sob a perspectiva do paradigma hermenêutico. Para tanto, apresentam-se os problemas que atingem o estudo das omissões inconstitucionais administrativas a partir de uma perspectiva normativa que incorpore o mundo prático, discutindo a ideia de normas constitucionais programáticas e as suas possibilidades de aplicação. Ainda nessa perspectiva, a delimitação do tema envolve as omissões inconstitucionais administrativas em um contexto de distanciamento (no sentido de autonomia) e aproximação (no sentido de diálogo) entre direito e política e seus impactos na apreciação judicial dessas omissões.

O presente trabalho parte de uma pesquisa bibliográfica associada com pesquisa documental jurisprudencial que tem como objetivo discutir as omissões inconstitucionais administrativas causadas pela proteção insuficiente de direitos fundamentais sob o prisma do paradigma hermenêutico.

Para atingir tal objetivo, em um primeiro momento, observa-se a evolução de modelos estatais que transitam de postura inertes a posturas inclusivas por parte do poder público. Esse ponto fica nítido ao tratar do Estado Liberal ao Estado Social e o "plus normativo" transformador que marca o modelo estatal designado como Estado Democrático de Direito.

Consultor Jurídico. 30 jul. 2016. Disponível em: < https://www.conjur.com.br/2016-jul-30/observatorioconstitucional-enfim-lei-mandado-injuncao?imprimir=1>. Acesso em: 15 out. 2016. 
Nesse contexto, torna-se relevante analisar o papel do Poder Judiciário enquanto concretizador de direitos fundamentais que envolve também uma leitura do Constitucionalismo Contemporâneo e a necessidade de efetivação de direitos fundamentais para uma democracia substancial.

Além disso, o estudo passa pela discussão da inconstitucionalidade por omissão ocasionada pela proteção insuficiente de direitos fundamentais, analisando as diferentes possibilidades de omissões inconstitucionais, bem como o julgamento da Ação Direta de Inconstitucionalidade por Omissão $n^{0} 1.698$ para suscitar o debate dos pontos abordados no contexto da jurisdição constitucional brasileira.

\section{O ESTADO DEMOCRÁTICO DE DIREITO E O PAPEL DO PODER JUDICIÁRIO NO CONSTITUCIONALISMO CONTEMPORÂNEO}

\subsection{Do Estado Liberal ao Estado Social}

Quando falamos de Estado estamos discutindo uma instituição que tem olhares distintos. O objeto "Estado" relata uma instituição histórica e dinâmica, não definitiva, possuindo origem e historicidade que merecem a devida atenção. Adota-se como ponto de partida o Estado Moderno que, na linha das colocações de Bolzan de Morais (1996, p. 76-84), consiste naquele que aparece unificado em um centro de tomada e implementação de decisões, caracterizado pelo poder soberano incontrastável sobre um território.

A partir do Estado Moderno, verifica-se a formação da dicotomia absolutista/liberal. Na sua modalidade absolutista, o Estado se identifica com a própria figura do monarca, enquanto o Estado Liberal é marcado principalmente pela limitação de poder, por garantias individuais e pelo livre desenvolvimento do mercado.

O triunfo do Estado Liberal, como fruto das revoluções liberais, significa a vitória da burguesia em seus anseios por ascensão econômica e social, marcando a derrocada do absolutismo. De acordo com Bolzan e Streck (2010, p. 95), o Estado Liberal possui as seguintes características: a primeira consiste na separação entre o Estado e a sociedade civil mediada pelo direito, este visto como um ideal de justiça; a segunda, na garantia das liberdades individuais os direitos fundamentais aparecem como mediadores das relações entre os indivíduos e o Estado; a terceira, no fato de que a "democracia surge vinculada ao ideário da soberania da nação produzido pela revolução francesa, implicando a aceitação da origem consensual do Estado"; por fim, o Estado passa a ter um papel reduzido, apresentando-se como Estado mínimo, assegurando, assim, a liberdade de atuação dos indivíduos. 
Este modelo liberal de Estado, no entanto, sofre desgaste em virtude de uma série de circunstâncias que culminam no surgimento do chamado Estado Social. A respeito do itinerário do Estado Liberal em direção ao Estado Social, são fundamentais as lições de Avelãs Nunes (2011, p. 59) quanto aos fatores que compõem esta transição. Primeiramente, o fato de que a Revolução Industrial aumentou a produtividade e a capacidade de criação de riqueza, mas também as desigualdades sociais: as cidades não ofereciam condições para receber tanta gente e a indústria não absorvia toda a massa de trabalhadores.

O sistema capitalista, ao articular-se com a indústria, demonstra a sua característica de ser alheio ao ideal de uma civilização igualitária, o que torna visíveis as suas contradições bem como a impossibilidade de mecanismos automáticos de regulação do mercado, servindo de fundamento para um governo democrático da economia. (AVELÃS NUNES, 2011, p. 61).

A teoria keynesiana aparece como contraponto aos economistas clássicos que lastrearam o pensamento econômico liberal: aponta o desemprego involuntário e a desigualdade natural de riqueza e rendimento como os dois vícios das economias capitalistas, vícios esses cuja correção seria responsabilidade do Estado. Segundo esta teoria, inspiradora da transição para o Estado Social, as desigualdades econômicas contrariam o desenvolvimento da riqueza e a própria manutenção da economia capitalista, de modo que seria possível conciliar o progresso social e a eficácia econômica. (AVELÃS NUNES, 2011, p. 67).

O Estado Social surge então como resposta à necessidade de intervenção do Estado na economia, em nome do princípio da responsabilidade social coletiva. Nesse sentido, é importante lembrar que este Estado Social, para Avelãs Nunes (2011, p. 67), não pretendia promover, assim como não promoveu, uma revolução social. Ele se enquadra, de fato, na lógica do capitalismo e um exemplo disso é o fenômeno da política de redistribuição do rendimento, por meio do qual o Estado provia prestações de direitos sociais, financiava o próprio desenvolvimento das forças produtivas, propiciando mão-de-obra mais qualificada, capaz de produzir mais, dando maior rendimento aos empregadores e propiciando vantagens aos donos do capital.

Nessa mesma linha, Garcia Pelayo (2009, p. 6) salienta que o Estado Social significa uma tentativa de adaptação do Estado Liberal burguês às condições sociais da civilização industrial e pós-industrial, com seus novos e complexos problemas; todavia, refere que "Não devemos ver as medidas criadas para permitir tal adaptação como algo totalmente novo, mas como uma mudança qualitativa de tendências surgidas no século XIX para regular, naquele momento, aspectos parciais da sociedade, regulação que passa, na atualidade, por um processo de generalização, integração e sistematização."

Este modelo de Estado tem como objetivo primordial harmonizar o princípio do mercado com o equilíbrio e os avanços sociais, mediante políticas de distribuição e redistribuição de 
ingressos, nivelação de patrimônios e de cargas e pleno emprego. Deve-se ressaltar, contudo, que o bom funcionamento da economia de mercado ainda é considerado como pressuposto básico do desenvolvimento social, e que essas políticas de redistribuição somente têm aceitação uma vez que não sejam obstáculo ao sucesso da economia. (GARCIA-PELAYO, 2009, p. 58).

Especificamente no contexto brasileiro, Celia Kerstenetzky (2012, p. 181) reconhece três ondas de inovação institucional e difusão de direitos sociais no Brasil: os anos de bem-estar corporativo, entre 1930 e 1964, nos quais foram implementadas as legislações trabalhistas e previdenciárias, fase que se estende de modo principalmente inercial e incremental entre $1946 \mathrm{e}$ 1964; o período de universalismo básico, compreendido entre os anos 1964 e 1984, quando se unificou e estendeu, de modo diferenciado, a cobertura previdenciária para extratos sociais tradicionalmente excluídos e se criou um segmento privado simultaneamente a um público na saúde, este último voltado para os não cobertos pelos segmentos contributivo e privado; e o período pós-1988, com a institucionalização da assistência social, a fixação de um mínimo social, a extensão da cobertura previdenciária não contributiva, a criação do Sistema Único de Saúde e a política de valorização do salário-mínimo.

A autora reconhece, no entanto, que a lentidão com que se desenvolveu no Brasil um Estado Social reflete a sua baixa prioridade nos projetos de desenvolvimento econômico em décadas precedentes. Boa parte do período formativo do Estado do bem-estar no país foi dominada por governos não democráticos pouco atentos a direitos sociais e a políticas inclusivas. Somente nos primeiros anos do século XXI é que o país finalmente começa a experimentar reduções significativas das desigualdades econômicas, após quase oito décadas de políticas pouco sensíveis à questão distributiva que deixaram um considerável passivo social. (KERSTENETZKY, 2012, p. 257).

A Assembleia Constituinte de 1987/1988 marca a redemocratização do Brasil e inaugura uma ampliação substancial no rol de direitos fundamentais de diversas dimensões, conferindo a estes direitos aplicabilidade imediata e proteção diante do poder de reforma. A Constituição brasileira de 1988 contribui, ainda, para o fortalecimento do Ministério Público como instituição, a ampliação do rol de legitimados para a propositura da ação direta de inconstitucionalidade e a institucionalização do controle de constitucionalidade por omissão.

Todos esses pontos são relevantes para destacar que o texto constitucional insere a garantia jurídica de uma partilha mais equitativa dos resultados econômicos. As instituições públicas, no entanto, têm sido retardatárias nesse processo, evoluindo muito lentamente, no que concerne à concretização dos direitos humanos e principalmente dos sociais. 


\subsection{O Estado Democrático de Direito e o "plus normativo"}

Como visto, o Estado Social agrega ao ideário liberal a questão social advinda dos conflitos inerentes ao modelo industrial desenvolvimentista, de forma que nesse modelo de Estado emergem garantias a prestações estatais positivas relativas aos direitos sociais.

Por Estado Democrático de Direito se entende, no sentido em que coloca Bolzan de Morais (2011, p. 30) um aprofundamento ou transformação de dois elementos: primeiramente do Estado de Direito e, por outro lado, da concepção de Estado Social. O autor define que, no paradigma do Estado Democrático de Direito, ao mesmo tempo em que se tem a permanência da questão social atrelada ao conceito de Estado Social ou Welfare State, há a sua qualificação pelo caráter transformador que agora se incorpora, que consiste no chamado "plus normativo". (BOLZAN DE MORAIS, 2011, p. 69).

O Estado Democrático de Direito aparece, portanto, como uma sucessão histórica do Estado de Direito, o qual já havia passado por seu nascedouro como Estado Liberal de Direito e, após, como Estado Social de Direito, marcado pelo enfrentamento dos dilemas socioeconômicos não resolvidos. (BOLZAN DE MORAIS, 2011, p. 49-50). Esse qualificativo de Estado tem como marca fundamental a sua finalidade de reestruturação social, o que confere novos contornos à já conhecida questão social. Esse modelo de Estado revela a necessidade de garantir a existência democrática das instituições, impedindo a volta dos regimes autoritários, atrelada à democratização das condições sociais, econômicas e culturais.

A definição do Estado Democrático de Direito passa, ainda, pela noção de que este tem como objetivo um projeto solidário de bem-estar, em que a atuação do Estado é tida com o teor de transformação do status quo, como um instrumento de mudanças sociais. Seu principal ator são as coletividades difusas, estando o ordenamento jurídico determinado ao desenho de instrumentos de garantia e implementação do futuro. (BOLZAN DE MORAIS, 1996, 72-75). Nesse paradigma, oriundo da síntese entre o Estado de Direito e o Estado Social, em que lhe é agregado um plus normativo, o Poder Judiciário passa a ser o centro pulsante da esfera de tensão entre os demais Poderes.

\section{O CONSTITUCIONALISMO CONTEMPORÂNEO E O PAPEL DO PODER JUDICIÁRIO NA CONCRETIZAÇÃO DE DIREITOS}

A expressão "Constitucionalismo Contemporâneo" surge no segundo pós guerra e é utilizada para designar a construção de um direito democraticamente produzido, sob o signo de uma constituição normativa e da integridade da jurisdição. (STRECK, 2012, p. 63). O fenômeno representa um redimensionamento político-jurídico no qual se busca limitar o exercício do poder 
a partir da concepção de mecanismos aptos a gerar e garantir o exercício da cidadania. (STRECK, 2017a, p. 37).

Ademais, o termo passa a ser utilizado no intuito de evitar ambiguidades que envolvem a utilização da expressão neoconstitucionalismo. O Constitucionalismo Contemporâneo traz ao ordenamento jurídico a inovação, uma vez que se distancia da ideia da ponderação alexyana, bem como do positivismo jurídico. Preocupa-se com a construção de uma sociedade justa e solidária; é um constitucionalismo distante das indiferenças e mais atento às injustiças sociais. (STRECK, 2014, p. 34).

$\mathrm{Na}$ ótica do Constitucionalismo Contemporâneo, o direito assume um elevado grau de autonomia; a moral, a política e a economia são elementos que passam a ser institucionalizados no Direito, criando-se, assim, um novo paradigma, incompatível com o positivismo jurídico nas sua mais variadas formas. (STRECK, 2017a, p. 39). Isso porque, além do problema da discricionariedade do positivismo normativista que é repetida pelo neoconstitucionalismo há ainda a questão da preservação da autonomia do direito que é essencial para uma democracia substancial ${ }^{4}$, conforme Lenio Streck $(2012$, p. 94) aponta que uma teoria do direito preocupada com a democracia substancial "deve conter/prever mecanismos para a preservação de um elevado grau de autonomia do direito, construindo 'blindagens' contra os predadores exógenos (moral, economia e política) e endógenos (panprincipiologismo, ponderação e as teses que apostam na 'abertura interpretativa dos princípios e cláusulas gerais')".

Deste modo, o Constitucionalismo Contemporâneo surge de um contexto de redemocratização e de discussão da vida política, que não pode ser sufocada pela atuação do Poder Judiciário. A este é atribuída a função de garantia e tutela dos direitos fundamentais no regime democrático, bem como de controle do exercício legal dos poderes públicos.

\footnotetext{
${ }^{4}$ A expressão "democracia substancial" tem como referência a teoria garantista de Luigi Ferrajoli, que traz a noção de democracia em suas dimensões formal e substancial. A democracia em sua dimensão formal ou procedimental é concebida tendo como base as formas e os procedimentos idôneos para garantir a vontade popular: tem como fundamento o quem (povo e seus representantes) e o como (a regra da maioria) das suas decisões, independentemente de seus conteúdos, quaisquer que eles sejam. Nesse sentido, a hipótese de um sistema no qual se decidisse por maioria a supressão de uma minoria seria, à luz desse critério, democrática. Essas contradições lógicas são apontadas para embasar a afirmação de que são necessários traços substanciais para toda definição teórica de democracia dotada de adequada capacidade explicativa. A democracia constitucional é, portanto, um paradigma complexo que adiciona à dimensão formal uma dimensão substancial da democracia, referente aos conteúdos ou à substância das decisões: aquilo que a qualquer maioria está, por um lado, proibido e, por outro, lhe é obrigatório decidir. Para Ferrajoli, essência do constitucionalismo e do garantismo, ou seja, daquilo que se chama democracia constitucional, reside precisamente no conjunto de limites impostos pelas constituições a todo poder, que postula em consequência uma concepção de democracia como sistema frágil e complexo de separação e equilíbrio entre poderes, de limites de forma e de substância a seu exercício, da garantia dos direitos fundamentais e de técnicas de controle e de reparação contra suas violações. Esta é a substância da democracia constitucional: o pacto de convivência baseado na igualdade de direitos, no Estado Social - mais que liberal - de Direito, garantido pelas Constituições, contendo obrigações para os legisladores, de cuja observância depende a sua legitimação. Ver FERRAJOLI, Luigi. Democracia y garantismo. Tradução de Perfecto Andrés Ibáñez et al. Madrid: Trotta, 2008. p. 76-78.
} 
Por conseguinte, no Estado constitucional de direito o legislador não é onipotente, no sentido de que as leis emanadas por ele não são válidas somente pelo fato de sua entrada em vigor, ou seja, por terem sido produzidas na forma estabelecida nas normas sobre sua produção, mas também por resultarem coerentes com os princípios constitucionais. Tampouco a política é onipotente, ao reverter a sua relação com o direito: também a política e a legislação, que é seu produto, subordinam-se ao direito.

Assim, já não é possível conceber o direito como instrumento da política, mas esta deve ser assumida como instrumento para a atuação do direito, especialmente dos princípios e dos direitos fundamentais inscritos nesse projeto, ao mesmo tempo jurídico e político, que é a constituição. (FERRAJOLI, 2008, p. 210).

No Constitucionalismo Contemporâneo o sistema político sofre transformações relativas à ampliação das funções próprias do Estado Social, provocadas pelo crescimento do seu papel de intervenção na economia e pelas novas prestações que demandam os direitos sociais constitucionalizados. Esse acúmulo de funções ocorre, entretanto, sem a previsão de garantias efetivas para os novos direitos, restando ausentes os mecanismos eficazes de controle político e administrativo. (FERRAJOLI, 2008, p. 211).

Este fenômeno atribui à jurisdição um novo papel: a defesa da legalidade frente ao abuso de poder. Esse papel é central, uma vez que a defesa da legalidade equivale à defesa do princípio da sujeição à lei de todos os poderes públicos, próprio do Estado de Direito, que é, por sua vez, pressuposto essencial da democracia. (FERRAJOLI, 2008, p. 212).

A atividade jurisdicional atua, nesse sentido, na sujeição à lei por parte de todos os poderes públicos e também como uma forma de limitação à democracia formal, procedimental, ou plebiscitária. Ferrajoli (2008, p. 212) entende a democracia em sua dimensão constitucional ou substancial, relativa ao conteúdo do que se é lícito decidir a maioria, ou não decidir, nem mesmo por unanimidade. Essa mudança de referenciais básicos é que oferece um novo fundamento democrático ao papel do juiz no Estado Democrático de Direito, não oposto, mas sim complementar à dimensão procedimental da democracia política.

\section{OMISSÕES INCONSTITUCIONAIS LEGISLATIVAS (NORMATIVAS) E ADMINISTRATIVAS (CONCRETAS)}

A partir da premissa de que os ditames constitucionais vinculam a atuação do poder público, desenvolvida nos tópicos anteriores, surge a necessidade de discutir as consequências da falta de atuação estatal diante das determinações constitucionais, em outras palavras, discutir as omissões inconstitucionais. 
Para tanto, parte-se primeiramente para uma análise de natureza terminológica, no que concerne ao órgão, poder ou função omissa. Isso porque, a ideia de inconstitucionalidade por omissão pode centrar-se tanto no órgão ou Poder responsável pela omissão inconstitucional, quanto centrar-se diretamente na função estatal omissa.

Na maioria da das vezes, essas duas perspectivas irão se confundir, no entanto é preciso cautela quanto às formas de violação negativa do texto constitucional. Quanto ao Poder ou órgão omisso, essa omissão poderá advir do Legislativo, Executivo ou Judiciário. Já em relação à função estatal omissa, a inconstitucionalidade por omissão poderá ser legislativa, administrativa ou jurisdicional. (FERNANDES, 2017, p. 193).

O presente estudo adota a definição de inconstitucionalidade por omissão a partir da função omissa que dê ensejo à omissão inconstitucional, tendo em vista que esta pode existir tanto em relação a atividades de natureza legislativa e jurisdicional quanto a atividades e natureza administrativa que possam de alguma forma afetar a efetividade de norma constitucional, mesmo porque há previsão constitucional expressa nesse sentido 5 . (BRASIL, 1988).

No tocante à jurisprudência do Supremo Tribunal Federal, é possível constatar a menção a omissões provocadas pelo "poder público", ou pelo "Estado", revelando o entendimento do Tribunal em abranger a totalidade das funções estatais uma vez constatada a inércia quanto às prestações determinadas pelo texto constitucional. Ao se manifestar a respeito das modalidades de comportamentos inconstitucionais por parte do poder público, aduziu o Tribunal Pleno do Supremo Tribunal Federal que a violação ao texto constitucional pode decorrer por ação estatal bem como por inércia governamental. (BRASIL, 1996, p. 128).

Nesse sentido, a inconstitucionalidade pode derivar primeiramente de um comportamento ativo do poder público (agindo ou editando normas em desacordo com a Constituição), ou seja, uma conduta estatal que está atrelada a uma atuação positiva (facere).

Por outro lado, se o Estado se mostra inerte, deixando de adotar as medidas essenciais à concretização, efetivação e exequibilidade dos ditames constitucionais, abstendo-se do cumprimento de obrigações positivas determinadas pela Constituição, estaremos diante de uma violação negativa ao texto constitucional que revela inconstitucionalidade por omissão (non facere ou non praestare), podendo esta ser total - quando nenhuma providência é adotada - ou parcial, quando a medida efetivada pelo Poder Público é insuficiente. (BRASIL, 1996, p. 128).

Da própria jurisprudência do STF é possível inferir, através da descrição genérica adotada, que não somente a inércia legislativa (isto é, a inércia quanto ao dever de legislar

\footnotetext{
${ }^{5}$ Conforme redação do art. $103, \S 2^{\circ}$ da Constituição Federal, “declarada a inconstitucionalidade por omissão de medida para tornar efetiva norma constitucional, será dada ciência ao Poder competente para a adoção das providências necessárias e, em se tratando de órgão administrativo, para fazê-lo em trinta dias".
} 
imposto por norma constitucional) poderá resultar em omissões inconstitucionais, esse raciocínio também pode ser evidenciado pela leitura da Ação Direta de Inconstitucionalidade por Omissão n. 1.698 .

Acrescenta-se que a redação do art. 103, $\S 2^{\circ}$ da Constituição (BRASIL, 1988) permite imputar à Administração Pública a pendência de providências que permitam a realização de normas constitucionais ${ }^{6}$. Nessa linha, a omissão de órgão administrativo pode estar relacionada à inatividade quanto à entrega de prestações sociais exigíveis com base em normas constitucionais definidoras de direitos, inclusive no que tange aos direitos sociais previstos no art. $6^{\circ}$, caput, da Constituição Federal. (FERNANDES, 2017, p. 197-198).

Para consolidar esse ponto de vista é também necessário ressaltar que a abordagem da omissão inconstitucional administrativa (aquela que deriva da inércia relativa à função estatal administrativa) não se confunde com o seu instrumento de controle de constitucionalidade, isso porque na maioria dos casos essas demandas serão tuteladas em Mandado de Segurança. (FERNANDES, 2017, p. 198, 277).

Nesse sentido, faz-se uma distinção entre o vício - a inconstitucionalidade por omissão - e seus instrumentos típicos de controle, especialmente quanto ao Mandado de Injunção e a Ação Direta de Inconstitucionalidade por Omissão. O que se quer deixar claro é que o presente estudo não se esgota na análise das omissões administrativas no plano processual ${ }^{7}$, voltando as suas atenções especialmente para as questões hermenêuticas envolvidas na apreciação judicial dessas omissões, bem como para o impacto dessas questões para o papel do Poder Judiciário no Constitucionalismo Contemporâneo.

\section{OMISSÕES INCONSTITUCIONAIS ADMINISTRATIVAS E O PROBLEMA DA PROTEÇÃO INSUFICIENTE DE DIREITOS FUNDAMENTAIS}

A Constituição de 1988 (BRASIL) tem como um de seus principais pontos de destaque, no plano normativo, o fato de voltar as suas atenções para a inconstitucionalidade ocasionada

\footnotetext{
${ }^{6}$ Art. 103, $\S 2^{\text {o }}$ da Constituição Federal, “declarada a inconstitucionalidade por omissão de medida para tornar efetiva norma constitucional, será dada ciência ao Poder competente para a adoção das providências necessárias e, em se tratando de órgão administrativo, para fazê-lo em trinta dias".

${ }^{7} \mathrm{O}$ estudo da concretização de direitos sociais, ainda que não costume ser enfrentada por meio dos instrumentos típicos do Mandado de Injunção e Ação Direta de Inconstitucionalidade por Omissão, é contemplado por alguns casos paradigmáticos enfrentados pela jurisdição constitucional: a decisão do STF que entendeu ser legítima a condenação do Poder Público a fornecer medicamentos a portadores do vírus HIV (BRASIL. STF. RE 271.2868/RS. Rel. Min. Celso de Mello. DJU 24/11/2000.); a decisão do Tribunal Regional Federal da $4^{\text {a }}$ Região que determinou ao SUS que realizasse cirurgias de alteração de sexo (BRASIL. TRF da $4^{\mathrm{a}}$ região. Apelação Cível n. ${ }^{\circ}$ 2001.71.00.026279-9/RS. Rel. Roger Raupp Rios.); A ADPF n. ${ }^{\circ} 45$, onde o Supremo ponderou em abstrato a possibilidade do controle jurisdicional das políticas, em face de elementos como a reserva do possível e a separação de poderes (BRASIL. STF. ADPF n. ${ }^{\circ}$ 45. Rel. Min. Celso de Mello. Julgado em 29 de abril de 2004.); Nesse sentido, ver: FERNANDES, Eric Baracho Dore. Omissões inconstitucionais e seus instrumentos de controle: contribuições para o aprimoramento institucional. Salvador: JusPodivm, 2017. p. 278.
} 
pela inércia na atuação dos entes públicos, classificada como "inconstitucionalidade por omissão" ou "omissões inconstitucionais". Isso pode ser demonstrado pela criação dos institutos da Ação Direta de Inconstitucionalidade por Omissão, ação do controle de constitucionalidade concentrado prevista no artigo $103, \S 2^{\circ}$ da $\mathrm{CRFB} / 88$, bem como da garantia constitucional do mandado de injunção, prevista no artigo $5^{\circ}$, LXXI, da CRFB/88.

Ocorre que, na concepção doutrinaria tradicionalmente repercutida no direito brasileiro, esse aprimoramento dos instrumentos judiciais de análise da inconstitucionalidade por omissão vem acompanhado de uma restrição teórica que se restringe à análise formal dessa modalidade de inconstitucionalidade, identificando este fenômeno pelo viés da estrutura semântica de aplicabilidade da norma ${ }^{8}$.

É possível observar, apesar disso, posicionamentos doutrinários que já se situam no plano da reconstrução das omissões inconstitucionais, abrangendo esta noção de forma a acolher o problema da eficiência na tutela de direitos fundamentais. Dentre outros, situam-se nesse prisma autores como Juarez Freitas (2012), Ingo Sarlet (2006) e Lenio Streck (2013).

$\mathrm{Na}$ esteira do que afirma Lenio Streck (2013, p. 891) "é necessário separar omissões legislativas resultante de violação de preceitos constitucionais concretamente impositivos do não cumprimento da Constituição derivado da não atuação de normas-fim ou normas-tarefa, abstratamente impositivas". A atividade administrativa abarca a aplicação da Constituição de modo a assegurar a eficácia dos direitos fundamentais no âmbito das políticas públicas. (FREITAS, 2012, p. 2).

A atuação administrativa desproporcional por excesso ou inoperância no atendimento dos direitos fundamentais não encontra guarida, portanto, nos moldes do Constitucionalismo Contemporâneo. Uma vez que o Estado se mostre inoperante na consecução de objetivos fundamentais consignados na Constituição Federal revelam-se omissões antijurídicas (visto que inconstitucionais) administrativas. (FREITAS, 2012, p. 10). Nas palavras de Juarez Freitas (2012, p. 12):

O omissivismo é causa de dano juridicamente iníquo, porque o princípio constitucional da proporcionalidade veda excesso e inoperância, em sede prestacional, isto é, na implementação das políticas de Estado e na concretização do direito fundamental à boa administração pública. Nesse sentido, os controles (interno, externo, social e judicial) de inconstitucionalidade vetam não apenas excessos, mas também inércias em

\footnotetext{
${ }^{8}$ Para uma análise mais acurada da concepção tradicional da doutrina brasileira a respeito das omissões inconstitucionais, ver: CAMPOS, Carlos Alexandre de Azevedo. Estado de coisas inconstitucional. Salvador: Jus Podivm, 2016.
} 
matéria de políticas públicas, prescritas pela Constituição, sem que isso configure o temido governo dos controladores. Por outras palavras, segundo essa ótica, os possíveis pontos de veto passam a incorporar, em crescente medida, os pontos de veto à omissão inconstitucional.

Observa-se, nesse ponto, a responsabilidade proporcional do Estado tendo como base tanto as ações quanto as omissões, o que possibilita o controle de constitucionalidade de atos normativos por omissão, tendo como parâmetro a determinação de normas autoaplicáveis, no caso de omissão inconstitucional por parte da Administração Pública, uma vez que a omissão estará na conduta do agente público que deveria conferir eficácia plena à norma no cumprimento de seu dever constitucional. (FREITAS, 2012, p. 31).

Nesse plano, o presente trabalho tem como objetivo discutir as questões hermenêuticas envolvidas nessa mudança de paradigma que tem como contexto não só a transformação textual provocada pela Constituição de 1988, mas também a própria ideia de que o constitucionalismo brasileiro está associado a um modelo estatal consignado em um Estado Democrático de Direito.

\subsection{A Ação Direta de Inconstitucionalidade por Omissão $n^{0} 1.698$ e a apreciação jurisdicional de omissões inconstitucionais administrativas}

A necessidade de enfrentamento teórico dessas questões ganha relevo, inclusive, no plano jurisprudencial, conforme pode ser observado pelo acórdão que julgou a Ação Direta de Inconstitucionalidade por Omissão $n^{0} 1.698$ (BRASIL, 2010), na qual constaram formalmente como requerentes o Partido dos Trabalhadores (PT), o Partido Comunista do Brasil (PC do B) e o Partido Democrático Trabalhista (PDT). Como requeridos, foram instados formalmente o Presidente da República e o Ministro da Educação.

A referida ação direta teve como objeto a análise de omissão atribuída ao Presidente da República que decorreria da inércia dessa autoridade, segundo os requerentes, em face do disposto nos artigos $6^{\circ}, 23, \mathrm{~V}, 208$, I, e 214, I, da Constituição da República, que estabelecem "a necessidade de erradicação do analfabetismo no País e a garantia da oferta e implementação perene de ensino fundamental obrigatório e gratuito para todos os brasileiros, inclusive para os que a ele não tiveram acesso na idade própria".

Na ocasião o Supremo Tribunal Federal apontou a omissão inconstitucional quando a autoridade deixa de agir para adotar determinada providência que torne eficaz direito constitucionalmente assegurado, evidenciando que o conceito de omissão inconstitucional significa não fazer aquilo a que, de forma concreta, se estava obrigado. Nesse sentido, "tem-se a omissão inconstitucional quando a autoridade competente para adotar determinada providência, 
que torne eficaz direito constitucionalmente assegurado, deixa de agir na forma prevista no sistema”. (BRASIL, 2010, p. 700).

O então Ministro Ayres Britto ressaltou que o seu entendimento não compactuava com a negação da possibilidade de controle de constitucionalidade por omissão de políticas públicas no campo da educação. (BRASIL, 2010, p. 710). A relatora Ministra Carmen Lúcia, por sua vez, aduziu que é inerente aos objetivos da referida ação o poder e dever de cobrar a adoção de políticas publicar que objetivem a erradicação total do analfabetismo formal e informal. (BRASIL, 2010, p. 710). Ao se manifestar afirmou o então Ministro Ayres Britto:

\begin{abstract}
Essa inflexão de Vossa Excelência, essa afirmativa de que é franqueado ao Supremo Tribunal Federal sindicar do cumprimento das políticas públicas que já estão definidas na própria Constituição, ainda que em linhas gerais, mas aqui até com percentuais mínimos, essa afirmativa de Vossa Excelência é que me parece colocar as coisas no devido lugar. O Supremo Tribunal Federal está exercendo, com legitimidade, um ofício de controle de constitucionalidade que, de fato, the cabe. Agora, como disse o Ministro Gilmar, trata-se de política pública predefinida, claro que não com todas as minudências, com todas as especificidades, na própria Constituição Federal. E a norma de fato é normaprograma ou norma-tarefa, segundo a melhor doutrina.
\end{abstract}

Ao final do julgamento, o Supremo Tribunal Federal foi uniforme em avaliar que muito ainda terá de ser feito para melhorar a qualidade da educação e para erradicar o analfabetismo no país, no entanto o Plenário do STF, por maioria, julgou improcedente a Ação Direta de Inconstitucionalidade $\mathrm{n}^{\mathrm{o}} 1.698$, tendo em vista que as políticas brasileiras de educação objetivariam aproximar o país do ideal, não se verificando, portanto, uma inércia do Poder Público. Discordante o voto do Ministro Marco Aurélio, que entendeu haver inconstitucionalidade por omissão tendo em vista os esforços do poder público em erradicar o analfabetismo no país serem empreendimento aquém do mínimo necessário. (BRASIL, 2010, p. $711)$.

A partir da observação da referida ação direta é possível observar um prognóstico de transformações em sede de controle constitucionalidade jurisdicional de omissões inconstitucionais administrativas. Isso porque a $\mathrm{ADO} \mathrm{n}^{\mathrm{o}} 1.698$ foi representativa em evidenciar um posicionamento da Corte Constitucional brasileira, primeiramente, pela possibilidade de que esse tipo de omissão seja sindicável em controle concentrado de constitucionalidade, o que demonstra a assunção do papel concretizador de direitos por parte do Poder Judiciário. 


\subsection{A inconstitucionalidade por proteção insuficiente em sede de direitos fundamentais}

Como visto, o Estado pode incorrer na inconstitucionalidade por meio da frustração ao seu dever de proteção, atuando de modo insuficiente, ou seja, deixando de atuar ou atuando abaixo de um nível mínimo de proteção constitucionalmente exigido. A ideia de omissões inconstitucionais está então vinculada à proibição de insuficiência (tradução do alemão Untermassverbot), ou seja, a vedação da insuficiente concretização dos deveres de proteção do Estado. O princípio da proibição de insuficiência atua, nesse sentido, como balizador da violação de deveres estatais inerentes à proteção de direitos fundamentais. (SARLET, 2006, p. 334).

Esse princípio aparece na jurisprudência do Tribunal Constitucional Federal da Alemanha quando do reconhecimento de que existe uma margem de atuação do legislador, que tem prevalência na escolha dos meios e definição de prognósticos. Caberia ao Tribunal Constitucional, no entanto, a verificação de satisfação de um padrão mínimo de proteção aos direitos fundamentais. (MARTINS, 2005, p. 112).

Considerou o Tribunal Constitucional Federal Alemão que há violação à proibição de insuficiência quando o poder público for omisso, mesmo que essa omissão for parcial, quanto ao cumprimento dos imperativos constitucionais que determinam deveres de proteção. Aduziu o Tribunal que o Estado deve intervir no plano fático e normativo em parâmetro suficiente para satisfazer o seu dever de tutela, alcançando uma proteção adequada e, como tal, efetiva em respeito à ideia de proibição de insuficiência. Para a consecução desse objetivo, mostra-se necessário um projeto de proteção que combine elementos de proteção preventiva e repressiva. (MARTINS, 2005, p. 276).

Nesse passo, a proibição de insuficiência alcança todos os órgãos estatais, de modo que os direitos fundamentais vinculem intensamente o poder público inclusive em seus órgãos jurisdicionais. (SARLET, 2006, p. 336). Lenio Streck (2017b, p. 262) lembra ainda que num Estado Democrático de Direito os bens juridicamente tutelados devem ser entendidos como direitos dos quais exsurge a dupla face na proteção dos direitos fundamentais (Übermassverbot proibição de excesso - e Untermassverbot - proibição de proteção insuficiente).

Explica o autor (STRECK, 2017, p. 572):

O sentido da proporcionalidade se manifestará de dois modos: ou a lei contraria a Constituição, porque o Estado se excedeu, ocasião em que se estará diante da proibição de excesso (Übermassverbot); ou a lei poderá ser inconstitucional, porque o Estado protegeu de forma insuficiente determinado direito, hipótese que se poderá invocar a Untermassverbot. Não há um locus privilegiado para a aplicação da "devida/necessária proporcionalidade". Necessariamente, ela 
estará relacionada à igualdade na proteção de direitos. Desproporcionalidades ocorrem por violação da isonomia ou da igualdade. Veja-se, desse modo, como se torna irrelevante epitetar a exigência de proporcionalidade como princípio ou não. Mas atenção: o sentido da desproporção - seja negativo (Übermassverbot) ou positivo (Untermassverbot) - somente poderá ser dado mediante a obediência da integridade do direito. Não é da subjetividade pura e simples do aplicador que, ad hoc, exsurgirá a (des)proporcionalidade. Isso implica afirmar que o "princípio da proporcionalidade" não é instrumento para decisionismos. Alguma regra do sistema restará adequada à concreta normatividade ou a regra estará nulificada, conforme os vários exemplos tratados no decorrer destas reflexões.

A inconstitucionalidade por omissão surge então para evitar tanto que o legislador ordinário quanto o Poder Executivo descumpra seus deveres constitucionais, fato que está diretamente relacionado ao "plus normativo" do Estado Democrático de Direito que veda a inércia dos poderes públicos. (STRECK, 2013, p. 891). Nesse sentido, utilizando os aportes de sua Crítica Hermenêutica do Direito, Lenio Streck (2013, p. 891) afirma que "a ação declaratória de inconstitucionalidade por omissão visa a proteger a força normativa da Constituição, estabelecendo barreiras contra um não atuar que, sendo produto de uma decisão política, tem consequências jurídicas (a inconstitucionalidade)".

Diante disso, é possível perceber que a inconstitucionalidade por omissão pode ser ocasionada por uma violação à proporcionalidade em sua faceta de vedação à proteção insuficiente, sem, no entanto, essa afirmação envolver a defesa de decisões ou medidas arbitrárias, uma vez que essa análise inclui necessariamente o respeito à integridade em sede de direitos fundamentais 9 .

\section{CONSIDERAÇÕES FINAIS}

O Estado Social significa, historicamente, a tentativa de adaptação do Estado Liberal burguês às condições sociais da civilização industrial e pós-industrial, com seus novos e

\footnotetext{
${ }^{9}$ Para desenvolver a noção de integridade, Dworkin em sua obra O Império do Direito recomenda que os juízes identifiquem os direitos e os deveres legais até onde for possível, sempre partindo da pressuposição de que eles expressam uma concepção coerente de justiça e equidade e que foram criados por um único autor. O direito como integridade, nesse sentido, é ao mesmo tempo o produto e a fonte de inspiração da prática jurídica, que deriva dos princípios de justiça, equidade e devido processo legal. Sendo assim, o direito como integridade demanda ao juiz que submeta a sua interpretação a uma teoria coerente que justifique uma rede de estruturas e decisões políticas em comunidade. A partir dessa afirmação pode se perceber que os conceitos trabalhados (tais como integridade, coerência, romance em cadeia, resposta correta) por Dworkin estão intrinsecamente interligados e compõem o seu conceito interpretativo de direito. Ver DWORKIN, Ronald. O Império do Direito. Tradução Jefferson Luiz Camargo. São Paulo: Martins Fontes, 2007. p. 271-272.
} 
complexos problemas. As medidas criadas para permitir tal adaptação, entretanto, não devem ser concebidas como algo totalmente novo, mas como uma mudança qualitativa de tendências: tratase de uma política não destinada exatamente a transformar a estrutura social, mas a manter a continuidade do sistema econômico capitalista após serem evidenciadas as suas contradições.

Esse modelo estatal, transmutado em Estado Democrático de Direito com a agregação do "plus normativo" consistente no intuito transformador da realidade social, sofre graves ataques com a difusão do neoliberalismo, que marca uma tendência à desregulamentação e revisão dos limites e das possibilidades do Estado e também da Constituição.

Nesse sentido, as contribuições de uma atividade jurisdicional associada à democracia em sua dimensão constitucional ou substancial, e o que confere essa substância ao sistema democrático são exatamente os direitos fundamentais. A atividade jurisdicional no Constitucionalismo Contemporâneo deve, então, assumir o caráter contramajoritário que possuem os direitos fundamentais, tutelando estes direitos, que devem permear a atividade de todas as instituições públicas.

Uma vez consolidado o papel no Poder Judiciário enquanto concretizador de direitos no Constitucionalismo Contemporâneo, aparece como consequência a possibilidade de apreciação jurisdicional das omissões inconstitucionais provocadas por omissões do poder público em proteger de modo suficiente o rol de direitos fundamentais característico do Estado Democrático de Direito. A observação do acórdão que julgou a Ação Direta de Inconstitucionalidade no 1.698 contribui para a discussão da importância de utilização do paradigma hermenêutico para a discussão do problema das omissões inconstitucionais. Nesse sentido, ganham relevo os pontos discutidos no presente trabalho especialmente no tocante à necessidade da devida concretização de direitos fundamentais por parte do poder público.

HERMENEUTICAL POSSIBILITIES TO THE JUDICIAL APPRECIATION OF ADMINISTRATIVE UNCONSTITUTIONAL OMISSIONS: the control of unconstitutional omissions in contemporary constitutionalism

ABSTRACT: This paper approaches the relation between unconstitutional omissions and the contemporary constitutionalism. Thus, it discusses the distinctions of different types of unconstitutional omissions, presenting the concepts that characterize administrative unconstitutional omissions. Secondly, this paper proposes the analysis of questions involving administrative unconstitutional omissions under the perspective of hermeneutic paradigm. Through bibliography and jurisprudence research, the objective is to discuss administrative unconstitutional omissions caused by deficient protection of fundamental rights, under the hermeneutic paradigm. In order to reach this objective, firstly, the paper considers the evolution of State models which develop from inertia to inclusive postures. Then, it is relevant to analyze the paper of Judiciary as a concretizator of fundamental rights, what also involves contemporary 
constitutionalism and the necessity of effectivity of fundamental rights to a substantial democracy. Also, the study discusses the unconstitutional omissions caused by deficient protection of fundamental rights, analysing the different possibilities of unconstitutional omissions, as well as the judgment of the Direct Action of Unconstitutional Omission $\mathrm{n}^{\circ} 1.698$, to raise the debate of the subjects discussed in the context of Brazilian constitucional jurisdiction.

KEYWORDS: unconstitutional omissions, contemporary constitutionalism, judicial power.

\section{REFERÊNCIAS}

AVELÃS NUNES, Antonio José. As voltas que o mundo dá: Reflexões a propósito das aventuras e desventuras do Estado social. Rio de Janeiro: Lumen Juris, 2011.

BOLZAN DE MORAIS, Jose Luis. Do Direito Social aos Interesses Transindividuais: O Estado e o Direito na Ordem Contemporânea. Porto Alegre: Livraria do Advogado, 1996.

BOLZAN DE MORAIS, José Luis; STRECK, Lenio Luiz. Ciência Política e Teoria do Estado. Porto Alegre: Livraria do Advogado, 2010.

BOLZAN DE MORAIS, Jose Luis. As Crises do Estado e da Constituição e a Transformação Espaço-Temporal dos Direitos Humanos. 2. ed. Porto Alegre: Livraria do Advogado, 2011.

BRASIL. Constituição da República Federativa do Brasil de 1988. Disponível em: $<$ http://www.planalto.gov.br/ccivil_03/constituicao/constituicao.htm>. Acesso em: $26 \mathrm{dez}$. 2018.

BRASIL. Supremo Tribunal Federal. Medida Cautelar na Ação Direta de Inconstitucionalidade $\mathrm{n}^{\circ}$ 1458. Tribunal Pleno. Requerentes: Confederação Nacional dos Trabalhadores na Saúde CNTS. Requeridos: Presidente da República; Congresso Nacional. Relatora: Ministro Celso de Mello. Brasília, 23 de Maio de 1996. p. 128. Disponível em: < http://redir.stf.jus.br/paginadorpub/paginador.jsp?docTP=AC\&docID=347068>. Acesso em: 14 out. 2017.

BRASIL. Supremo Tribunal Federal. Ação Direta de Inconstitucionalidade por Omissão $\mathrm{n}^{\circ}$ 1.698. Tribunal Pleno. Requerentes: Partido dos Trabalhadores (PT); Partido Comunista do Brasil (PC do B); Partido Democrático Trabalhista (PDT). Requeridos: Presidente da República; Ministro de Estado da Educação. Relatora: Ministra Carmen Lúcia. Brasília, 25 de fevereiro de 2010. Disponível em: <

http://redir.stf.jus.br/paginadorpub/paginador.jsp?docTP=AC\&docID=610036>. Acesso em: 24 maio 2017.

CAMPOS, Carlos Alexandre de Azevedo. Estado de coisas inconstitucional. Salvador: JusPodivm, 2016.

CARBONELL, Miguel. Presentación: El neoconstitucionalismo en su laberinto. In:

CARBONELL, Miguel (Org.). Teoría del neoconstitucionalismo. Ensayos escogidos. Madrid:

Editorial Trotta, 2007.

COÊLHO, Marcus Vinícius Furtado. "Mandado de injunção e efetividade dos direitos e liberdades constitucionais”. Consultor Jurídico, 5 dez. 2016. Disponível em: < 
https://www.conjur.com.br/2016-dez-05/mandado-injuncao-efetividade-direitosliberdades?imprimir=1>. Acesso em: 15 out. 2016.

DWORKIN, Ronald. O Império do Direito. Tradução Jefferson Luiz Camargo. São Paulo: Martins Fontes, 2007.

FERNANDES, Eric Baracho Dore. Omissões inconstitucionais e seus instrumentos de controle: contribuições para o aprimoramento institucional. Salvador: JusPodivm, 2017.

FERRAJOLI, Luigi. Democracia y garantismo. Tradução de Perfecto Andrés Ibáñez et al. Madrid: Trotta, 2008.

FREITAS, Juarez. Por uma hermenêutica superadora da omissão inconstitucional nas políticas públicas. In: Juarez Freitas; Anderson V. Teixeira. (Org.). Comentários à Jurisprudência do STF - Direitos Fundamentais e omissão inconstitucional. 1 ed. Barueri, São Paulo: Manole, 2012. p. 1-19.

GARCÍA-PELAYO. As Transformações do Estado Contemporâneo. Tradução Agassiz Almeida Filho. 2 ed. Rio de Janeiro: Forense, 2009.

KERSTENETZKY, Celia Lessa. O Estado do Bem-Estar Social na idade da razão: a reinvenção do Estado Social no mundo contemporâneo. Rio de Janeiro: Elsevier, 2012.

MARTINS, Leonardo (Org.). Cinqüenta Anos de Jurisprudência do Tribunal Constitucional Federal Alemão. Montevidéu, Uruguai: Fundação Konrad Adenauer, 2005. v. 1.

MORAIS, Jose; BRUM, Guilherme. Políticas públicas e jurisdição constitucional: entre direitos, deveres e desejos. Porto Alegre: Livraria do Advogado, 2016.

SARLET, Ingo Wolfgang. "Constituição, proporcionalidade e direitos fundamentais: o direito penal entre proibição de excesso e de insuficiência". Anuario Iberoamericano de Justicia Constitucional, Madrid, n. 10, p. 303-354, 2006.

STRECK, Lenio Luiz. Neoconstitucionalismo, positivismo e pós-positivismo. In: FERRAJOLI, Luigi et al. (Org.). Garantismo, hermenêutica e (neo)constitucionalismo: um debate com Luigi Ferrajoli. Porto Alegre: Livraria do Advogado, 2012.

STRECK, Lenio Luiz. Jurisdição constitucional e decisão jurídica. 3 ed. São Paulo: Editora Revista dos Tribunais, 2013.

STRECK, Lenio Luiz . "O que é isto - o constitucionalismo contemporâneo". Revista do CEJUR/TJSC: Prestação Jurisdicional, v. 1, n. 02, p. 34, out. 2014.

STRECK, Lenio Luiz. Constitucionalismo contemporâneo. In: Dicionário de hermenêutica: quarenta temas fundamentais da teoria do direito à luz da crítica hermenêutica do Direito. Belo Horizonte: Letramento: Casa do Direito, 2017a.

STRECK, Lenio Luiz. Verdade e Consenso: constituição, hermenêutica e teorias discursivas. 6 . ed. rev e ampl. São Paulo: Saraiva, 2017b. p. 262.

TASSINARI, Clarissa. Jurisdição e ativismo judicial: limites da atuação do Judiciário. Porto Alegre: Livraria do Advogado, 2013. 
VALLE, André Rufino do. "Até que enfim, uma lei para o Mandado de Injunção". Consultor Jurídico, 30 jul. 2016. Disponível em: < https://www.conjur.com.br/2016-jul-30/observatorioconstitucional-enfim-lei-mandado-injuncao?imprimir=1>. Acesso em: 15 out. 2016.

Trabalho enviado em 31 de dezembro de 2018

Aceito em 06 de fevereiro de 2020 